\title{
TOWARD A PSYCHOLOGY OF POSITIVE YOUTH DEVELOPMENT
}

\author{
Reed W. Larson, \\ University of Illinois at Urbana-Champaign
}

With kind permission from American Psychological, Inc.: American Psychologist, Toward a Psychology of Positive Youth Development, Vol. 55(1), 2000, 170-183, Larson, R., () American Psychological Association, Inc.

This article analyzes the development of initiative as an exemplar of one of many learning experiences that should be studied as part of positive youth development. The capacity for initiative is essential for adults in our society and will become more important in the 21st century, yet adolescents have few opportunities to learn it. Their typical experiences during schoolwork and unstructured leisure do not reflect conditions for learning initiative. The context best suited to the development of initiative appears to be that of structured voluntary activities, such as sports, arts, and participation in organizations, in which youths experience the rare combination of intrinsic motivation in combination with deep attention. An incomplete body of outcome research suggests that such activities are associated with positive development, but the developmental processes involved are only beginning to be understood. One promising approach has recorded language use and has found that adolescents participating in effective organizations acquire a new operating language that appears to correspond to the development of initiative.

It cannot be said, as for other domains of psychology, that developmental psychology has neglected the positive. Development, after all, is a process of growth and increasing competence. In the important subdomain of social and emotional development, however, we are often more articulate about how things go wrong than how they go right. We have a burgeoning field of developmental psychopathology but have a more diffuse body of research on the pathways whereby children and adolescents become motivated, directed, socially competent, compassionate, and psychologically vigorous adults. Corresponding to that, we have numerous research-based programs for youth aimed at curbing drug use, violence, suicide, teen pregnancy, and other problem behaviors, but lack a rigorous applied psychology of how to promote positive youth development.

The place for such a field is apparent to anyone who has had contact with a cross section of American adolescents. In such a group, one encounters a surprising number of youth who appear to be bored, unmotivated, and unexcited about their lives. This malaise was brought home to me when we obtained a random sampling of self-reports on 16,000 moments in the daily experience of a representa- 
tive sample of White, working- and middle-class young adolescents-a group that seemingly has everything going for them. These youth reported feeling bored for $27 \%(4,300 !)$ of these random moments (Larson \& Richards, 1991). Of course, individuals differed in these rates, but what was surprising was that honor students were as likely as those involved in delinquent activities to be among those reporting high rates of boredom, in many cases for more than $50 \%$ of the random moments. The litany of explanations for this boredom-" algebra sucks, "'I'I'm always bored on Sunday,"'"'there's nothing to do,"'"the Odyssey is boring" —reads like a script from Bart Simpson. They communicate an ennui of being trapped in the present, waiting for someone to prove to them that life is worth living.

High rates of boredom, alienation, and disconnection from meaningful challenge are not signs of psychopathology, at least not in most cases, but rather signs of a deficiency in positive development. The same might be said for many cases of problem behavior, such as drug use, premature sexual involvement, and minor delinquency — that they are more parsimoniously described, not as responses to family stress, emotional disturbance, or maladaptive cognitions, but rather to the absence of engagement in a positive life trajectory. Many youth do their schoolwork, comply with their parents, hang out with their friends, and get through the day, but are not invested in paths into the future that excite them or feel like they originate from within. A central question of youth development is how to get adolescents' fires lit, how to have them develop the complex of dispositions and skills needed to take charge of their lives. This calling is made particularly difficult by the absence of a well-developed body of relevant theory and research regarding these dispositions and skills.

In this article, I am going to focus on adolescents' development of initiative, which I see as a core quality of positive youth development in Western culture. The construct initiative is closely related to capacity for agency or for autonomous action that others have discussed (Brandtstadter, 1998; Deci, 1995; Ryan, 1993). It consists of the ability to be motivated from within to direct attention and effort toward a challenging goal. In addition to being an important quality in its own right, I believe that initiative is a core requirement for other components of positive development, such as creativity, leadership, altruism, and civic engagement.

How does initiative develop? After situating this question in a cultural context, in the first section, I argue that initiative must emerge at least partly from adolescents' daily experiences, from the sparks of excitement and absorption that occur in their ordinary lives. In the following section, I examine how adequately the dominant daily activities of adolescents - schoolwork and unstructured leisure-produce the requisite elements. I conclude, as the boredom findings suggest, that Western adolescent life does not provide abundant daily opportunities for the experience and development of initiative.

In the middle part of the article, my focus turns to youths' experiences in structured leisure activities, such as arts, sports, hobbies, and participation in organi- 
zations. These activities account for only a small fraction of adolescents' time, but preliminary evidence suggests they are a context in which the elements of initiative often coalesce and an operating language of initiative develops. Readers may know that there is a loosely defined field of practice called youth development that is concerned with these types of activities and that positive youth development is currently a hot term in this field (Carnegie Council on Adolescent Development [Carnegie], 1992). But, regrettably, this field has evolved separately from developmental psychology (partly because we psychologists have had little to offer) and has not had a strong base of research and theory, especially regarding positive youth development (Brown,1988; Dubas \& Snider, 1993; Oden, 1995; Roth, Brooks Gunn, Murray, \& Foster, 1998). The final section of this article envisions a new domain of developmental knowledge that is integrated with this applied field and is aimed at facilitating positive development.

\section{INITIATIVE IN A WESTERN CULTURAL CONTEXT}

Given the renewed ideology of enterprise capitalism in U.S. and Western society, the importance of initiative hardly needs selling. The economic, social, and political order of our society presupposes an individual who is capable of autonomous action. Furthermore, we are moving into a new millennium in which changes in the occupational, interpersonal, political, and moral realms will demand new reserves of adaptation and creativity. In the last 50 years, we have already seen the wage value of rote, repetitive, and manual labor fall, as much of this labor is replaced by machines, and daily behavior, it appears, is less shaped by shared normative habits and goals than in the past (Oettingen, 1997). In the emerging heterogeneous global society where job demands and basic life course and life-style decisions are not preconfigured, adolescents will need to acquire the motivation and skills to create order, meaning, and action out of a field of ill-structured choices. Individuals will need the capacity to exert cumulative effort over time to reinvent themselves, reshape their environments, and engage in other planful undertakings. A generation of bored and challenge-avoidant young adults is not going to be prepared to deal with the mounting complexity of life and take on the emerging challenges of the 21st century.

Yet although the capacity for initiative is a presupposition of adult membership in our society, it is by no means a guaranteed result of our childhood and adolescence. In fact, it has been argued that the route to becoming an autonomous, agentic adult in our culture is problematic. The anthropologist Ruth Benedict (1938) observed that many traditional societies provide a progressive set of steps that socialize youth into the roles and responsibilities of adulthood, whereas in Western society there is marked discontinuity between what we expect of children and what we expect of adults, especially with regard to initiative. Benedict pointed out that children in our society are treated as dependent and given few responsibilities, whereas adults are required to be independent and suddenly take charge of all parts 
of their life-to a much greater degree than in other societies (cf. Sampson, 1988). In a similar vein, anthropologists Schlegel and Barry (1991) found that American and European adolescents carry less responsibility and are given fewer occasions to engage in consequential and planful action than are adolescents in most other societies of the world. They experience little societal support or scaffolding to practice and develop initiative. They have few experiences of "preparing, planning, executing, and assessing" an endeavor (Heath, 1999, p. 64). It is not surprising, then, that young adults in our society fail to carry through on a high rate of the intentions they set for themselves (Gollwitzer, 1999).

One way that initiative might be instigated would be if adolescents were "pulled" by appealing images of adulthood. They might then be motivated to set themselves on a course of action aimed at reaching adult goals. Except for sports heroes, however, adolescents have few models of adults they seek to emulate (Balswick \& Ingoldsby, 1982; McCormack, 1984); the prospect of current adult careersfor example, becoming a systems analyst, marketing specialist, or health technician-is not likely to inspire initiative. Recent commentators have also noted that the path into adult occupations is opaque to young people. Many poor and minority youth have little contact with successful adult models (Wilson, 1996) and perceive the transition into middle-class adulthood to be blocked (Ogbu, 1991). Yet, even for advantaged middle-class American youth, the steps required to gain entrance to many occupations are opaque (Hamilton, 1994; Schneider \& Stevenson, 1999). Whereas an optimistic vision of the future can be an important influence on adolescents' choices (Nurmi, 1991; Seligman, 1990), images of adult careers do not have enough magnetic pull, in and of themselves, to motivate most adolescents to begin taking control of their lives.

The development of initiative, I believe, needs to at least partly originate from adolescents' experiences in the present moment. Rather than just being pulled, it needs to be propelled. Especially given that the future is unstable (e.g., that many current occupations may not exist in 20 years), it is better if adolescents are motivated by the process of initiative, rather than by anticipated long-term rewards. For this to happen, adolescents need a series of experiences and opportunities, a la Benedict (1938), that build their development of this capacity.

What opportunities do youths have? In what contexts do Western adolescents experience elements of initiative in their daily lives? First, let me elucidate what I think these elements are. I see three elements as crucial. To begin with, initiative involves intrinsic motivation, the experience of wanting to be doing an activity and being invested in it. Agency entails the experience that one's thoughts and actions originate voluntarily from the self (Ryan, 1993; Ryan, Sheldon, Kasser, \& Deci, 1996). But intrinsically motivated action in a vacuum, or the confines of a solipsistic, self-created, or delusional world does not constitute initiative.

The second requirement is that this intrinsic motivation be experienced in association with concerted engagement in the environment, with exertion of constructive 
attention in a field of action involving the types of constraints, rules, challenge, and complexity that characterize external reality. In defining this second element, I draw on various constructs from Csikszentmihalyi (1978, 1993, 1996; Csikszentmihalyi \& Larson, 1984). Attention means devotion of thought and effort. Constructive attention means that this thought and effort is not random but directed toward creating some form of order, synergy, or negentropy. And this order or negentropy must be definable within an objective universe, within a field of externally recognizable challenge and complexity.

The third requirement is that this motivation and concerted engagement occur over time. Initiative involves a temporal arc of effort directed toward a goal, an arc that might include setbacks, re-evaluations, and adjustment of strategies. It is the capacity to carry out what Brian Little $(1983,1998)$ describes as a"serial" or"personal project." Despite its root in initiate, initiative is not just starting things but sticking with them. To be an agentic adult, one needs to be able to mobilize one's attention, one's mental powers, on a deliberate course of action, without being deterred by the first obstacle one encounters. Initiative is the devotion of cumulative effort over time to achieve a goal.

For initiative to develop, I believe that all three of these elements need to come together. An individual needs to experience the three in consort and learn to regulate them. Adolescence may be a particularly valuable time for the development of initiative, because the acquisition of hypothetico-deductive or formal-operational reasoning facilitates the growth of metacognitive strategies for selfregulation of psychological states and action over time (Brandtstadter, 1998; Lerner \& BuschRossnagel, 1981).

\section{Contexts of Adolescents' Daily Experience}

Where do these elements of initiative occur in adolescents' lives? In what contexts might these three elements come together? My colleagues' and my research provides a broad view of the different experiential contexts that fill adolescents waking hours and includes data bearing on the first two elements of initiative.

One major block of adolescents' daily experience is schoolwork. Schools are institutions deliberately created by society to prepare youth for adulthood, so one might hope they would foster this important capacity. In the United States and Europe, schoolwork, including classwork and homework, accounts for an average of $25-30 \%$ of adolescents' waking hours (Larson \&Verma, 1999). However, our data and that of many others indicate that this is a limited context for experiencing the elements of initiative.

The limits of the school context are evident in the psychological states adolescents report during schoolwork. In our research, we have had adolescents carry electronic pagers or alarm watches for one week and report on their activities and experiential states at random times when signaled by the pagers, following the procedures of the experience sampling method. We find that during classwork and 
homework, adolescents experience high levels of concentration (Figure 1), as well as high challenge. To me, this is evidence (albeit incomplete) of the second element of initiative: that they are exerting effort in an environment of challenge and complexity. But although this element is present, the first element is not. During schoolwork, adolescents report low intrinsic motivation (Figure 1). They also report high rates of boredom, and, although they report high concentration, they report difficulty in concentrating. Research by others using the same methodology also finds this pattern of concentration without intrinsic motivation during schoolwork (Csikszentmihalyi, Rathunde, \& Whalen, 1993; Leone \& Richards, 1989; Carli, Delle Fave, \& Massimini, 1988). This is a context of what Gibson and Rader (1979) called "other-directed attention." It is mental effort that is under the control of incentives and structuring provided by adults.
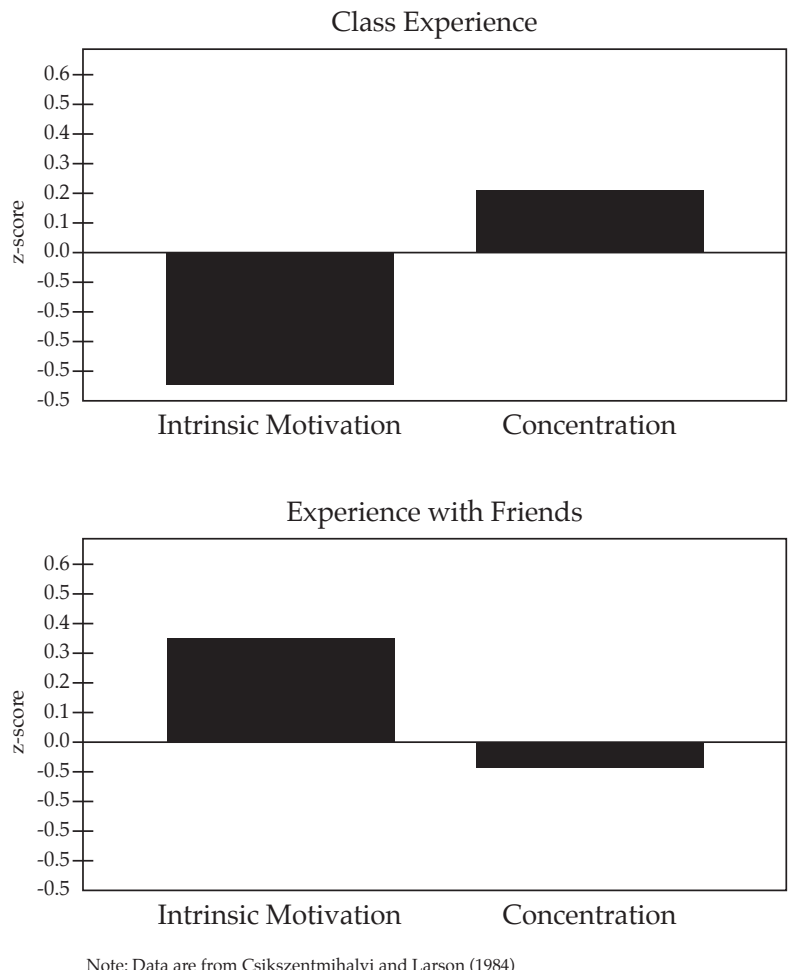

Figure 1: High-School-Aged Adolescents' Average Ratings of Their Psychological States in Class and With Friends 
This comparative absence of intrinsic motivation suggests that schoolwork is usually not a context conducive for the development of initiative. Indeed, the profile of experience just described appears to become less favorable as children advance into adolescence. We found that 15 -year olds reported lower levels of concentration and intrinsic motivation during schoolwork than 10-year-olds, both on an absolute scale and in comparison with other domains of their daily experience (Larson, Ham, \& Raffaelli, 1989; Larson \& Kleiber, 1993b). Other studies confirm the reduction in intrinsic motivation between the elementary and junior high school grades (Eccles, Wigfield, \& Schiefele, 1998) and provide behavioral evidence of reduced effort, showing a decline in school grades across this period (Eccles \& Midgley, 1991; Simmons \& Zhou, 1994). In observational research, Eccles and Midgley (1991) found that junior high classrooms provided fewer opportunities for student decision making than elementary schools. Although students are older and more capable of making decisions, the junior high school environment appears to provide fewer, not more, opportunities for the exercise of initiative.

My aim here is not to be critical of schools. There are many constraints on teachers, including large class sizes and an obligation to cover a broad ranging curriculum, that make it difficult to give students latitude to steer their own course. A number of researchers have suggested and demonstrated ways that schoolwork can be made to be intrinsically motivating (Anderman \& Maehr, 1994; Csikszentmihalyi, 1993; Deci \& Ryan, 1985). And there are parts of adolescents'schoolwork in which many do experience all three elements of initiative, for example, in doing independent research projects (Larson, 1985). But in the current reality, we need to look to other contexts of adolescents' lives to find consistent convergence of the elements of initiative.

Besides schoolwork, the other major block of adolescents' waking time is leisure. In the United States and Europe this discretionary activity accounts for a large expanse of time, $40-50 \%$ of waking hours during the school year and more during the summer (Larson \& Verma, 1999). Because leisure is self-controlled, one might expect that it provides unique opportunities for the development of personal agency (Silbereisen, Noack, \& Eyferth, 1986). One large segment of this time, however, is watching TV, accounting for 7-14\% of the average adolescents' waking hours (Larson \& Verma, 1999). Adolescents typically report high intrinsic motivation when watching TV, however, they do not report high concentration or challenge (Larson et al., 1989; Larson \& Kubey, 1983), nor is it associated with effort over time. So it is hardly a context of initiative.

A large proportion of Western adolescents'leisure time is spent in activities with peers, mainly talking and hanging out. Might this be a context for the experience and development of initiative? Our data indicate that, on average, this context does yield some of the requisite features of objective experience. Adolescents report high intrinsic motivation (Figure 1), as well as ease of concentration. But they report low 
concentration (Figure 1), as well as low challenge. In Dewey's (1913) terminology, this is "spontaneous attention," a type of engagement that children show in play. It is intrinsically motivated but does not involve concerted effort in a domain of challenge and complexity. Our data suggest that interactions with friends resemble positive feedback systems; ongoing feedback from friends is open, accepting, and uncritical, thus imposing limited reality constraints (Larson, 1983). Although there are certainly higher order challenges in negotiating peer relationships, most immediate interactions with friends do not appear to involve concerted engagement with challenge and complexity.

In conclusion, the great majority of adolescents' time is spent in two opposite experiential situations. In schoolwork, they experience concentration and challenge without being intrinsically motivated. In most leisure, including watching TV and interacting with friends, they experience intrinsic motivation but not in a context of concentration and challenge. Neither provides the combination of both of these elements necessary for the experience and development of initiative. There is, however, one small segment of adolescents'time that combines intrinsic motivation and concerted attention.

\section{Structured Voluntary Activities}

This one exception is a category we call structured voluntary activities, or youth activities for short. It includes activities that are organized by adults, such as extracurricular school activities and community youth activities, as well as structured activities that youth participate in on their own-such diverse things as hobbies, writing poetry, constructing a web site, or playing in a band with a group of friends. Our defining criteria for this category is activities that are voluntary (i.e., not required for school) and involve some structure, that is, where students' participation occurs within a system involving constraints, rules, and goals. Sports are the most frequent activity in this category, accounting for an average of 4-6 hours per week of U.S. adolescents' time (Csikszentmihalyi \& Larson, 1984; Kirshnit, Ham, \& Richards, 1989) and somewhat less in most European countries (Alsaker \& Flammer, 1999). Other activities, including arts, music, hobbies, and participation in organizations, account for a total average of 1-2 hours per week, with variations across Western nations (Larson \& Verma, 1999). These rates, it should be noted, do not include summertime, when structured voluntary camps, classes, and sports leagues fill a larger portion of time for adolescents from middle-class and affluent families. 

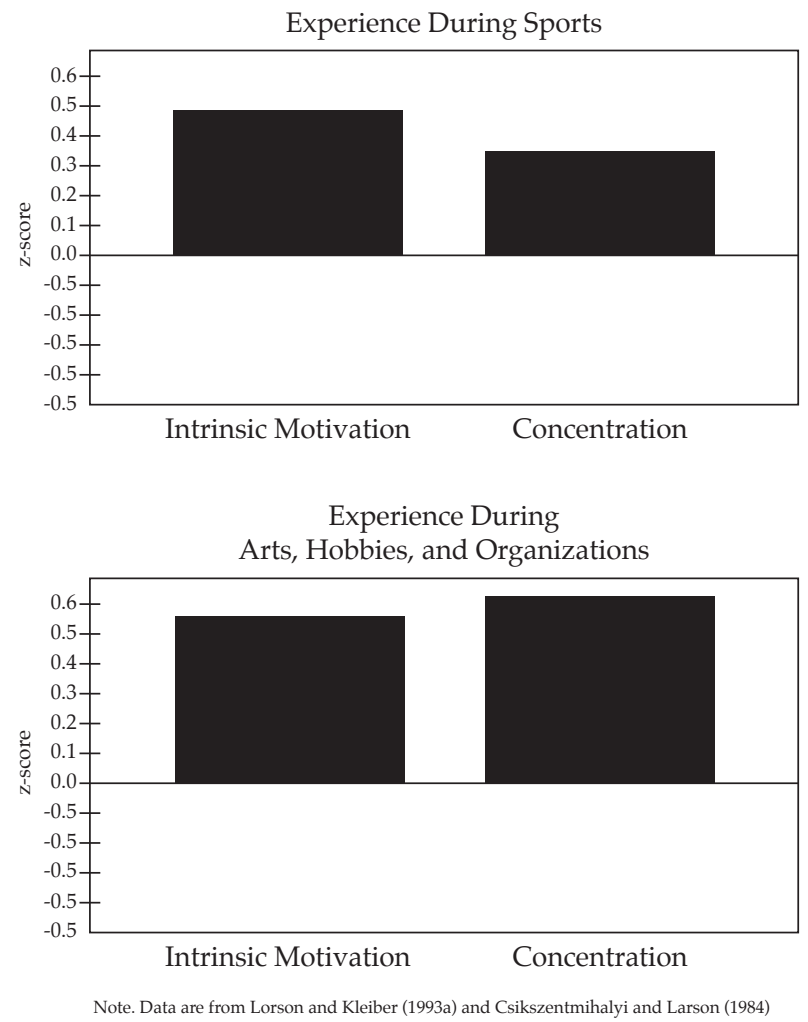

Figure 2: High-School-Aged Adolescents' Average Ratings of Their Psychological States During Structured Voluntary Activities

As Figure 2 shows, the immediate experience associated with these activities includes both high intrinsic motivation and concentration. We see this for sports and for arts, hobbies, and organizations. In both contexts, students also reported that concentration was easier than at other times and reported experiencing very high average challenge (Larson \& Kleiber, 1993a). This conjoint pattern has been replicated in our study of urban African-American young adolescents (Richards \& Larson, 1998) and in other studies of adolescents (Csikszentmihalyi et al., 1993; Larson \& Kleiber, 1993a). This co-occurrence of motivation and attention, suggests what Dewey (1913) called"voluntary attention" and Gibson and Rader (1979) called "self generated attention": attention that adolescents themselves direct. In an interview about experiences during this type of activity, one 9th grader described feeling "real strong and in control, like I could do anything." Adolescents' subjective 
involvement in these activities also resembles what Csikszentmihalyi $(1975,1990)$ calls flow; another 9th grader said, "You change, you forget everything around you."

This profile of experience, then, fits my first two criteria for initiative, intrinsic motivated effort in a context of complexity. Adolescents are highly motivated paying attention within a domain of challenges. We also found that the correlation between reported motivation and attention increased with age during these activities, which suggests that adolescents may be learning to coordinate these two elements (Larson et al., 1989). Indeed, in interviews, older adolescents reported exerting more control and self-regulation of these elements than did younger adolescents.

Our momentary sampling data do not provide direct substantiation of the third element of initiative: an arc of effort over time. But this arc is inherent in many of these activities. Many involve cumulative planning and action for the duration of a project or season (Heath, 1994; Larson \& Kleiber, 1993b). They have the quality of Little's (1983) "personal projects," involving concerted effort over time toward an outcome.

A richer picture of this temporal arc of agentic action is provided by Rogoff, Baker-Sennett, Lacasa, and Goldsmith's (1995) observations on the experience of Girl Scouts engaged in a campaign to sell cookies. They observed that these girls, both singly and in small groups, developed plans for their sales that included rehearsal of their sales pitch and development of spatial routes through the neighborhoods. As they gained experience, they then adjusted their plans and strategies. Sales pitches became more refined, their methods for keeping track of orders became more systematic, and they took over responsibilities initially held by their mothers. The temporal course of their involvement included monitoring their activities and self-regulation: they modified their strategies in response to feedback from their experiences. Rogoff et al. also emphasized that this process of learning was collaborative - with parents, peers, and customers - and they provided a useful warning that development of initiative is not necessarily an individual process, but rather often involves this type of collaborative agency.

As a whole, these findings begin to suggest that structured voluntary activities are a context that is particularly suited to the development of initiative. The presence of intrinsic motivation, concerted engagement, and, in many cases, a temporal arc, suggests that participants in these activities are having experiences of directing and regulating their actions in pursuit of a goal. Such experiences, I believe, are likely to stimulate the learning of initiative dispositions and skills. The process of creating order or negentropy within the activity, I suspect, promotes secondary processes of change within individuals (personal negentropy), change that facilitates this type of endeavor in the future.

For me, the phenomenological profile that we discovered for these activities inspires further theorizing. The unique combination of psychological states, intrinsic motivation with concentration, suggests that adolescents are awake, alive, and open to developmental experiences in a way that is less common in other parts of their 
daily lives. Research suggests that positive states are associated with more global and integrative thinking (Isen, 1987; Isen \& Means, 1983) and that they can be"organizers of development" (Collins \& Gunnar, 1990; Hauser \& Smith, 1991). I believe that this unique combination of agentic states may make these activities a fertile context for adolescents to develop and teach themselves a wide range of positive competencies, in addition to initiative.

Such unbridled enthusiasm, however, has a long history in the discussion of youth activities and has often strained credibility. Proponents have frequently made uncritical claims that youth activities build character, redirect aggressive impulses, and promote initiative, without subjecting these claims to the test of falsifiability. We must ask, then, where is the beef? What is the evidence that participation in these activities is related to measurable developmental change?

\section{Outcome Research}

Existent evaluation research on structured youth activities has typically dealt with the question of outcomes in general terms. It has examined outcomes from activity participation for broad, generic adjustment variables, without specifically focusing on initiative, and often without any theoretical base.

The history of these studies provides a textbook example on the difficulties of conducting truly critical outcome research. A substantial fund of cross-sectional, correlational research at first blush would seem to substantiate the claims that youth activities are related to positive developmental change. Participation in school extracurricular activities and community youth organizations has been found to be correlated with higher self-esteem, feelings of control over one's life, lower rates of delinquency, and higher educational aspirations and achievement (Holland \& Andre, 1987; Larson, 1994). The problem with these correlational relationships, however, is that research also suggests that youths' participation in these activities is selective. Participation is greater among higher socioeconomic status (SES) and higher abilitytracked students, who have more parental support (Butcher, 1985; Carnegie, 1992; Holland \& Andre, 1987; McNeal, 1995; Winnie \& Walsh, 1980). These are factors that predict positive outcomes on their own, so they represent a confound in the interpretation of correlational findings. Once these factors are controlled, the relationships between participation and positive outcomes are reduced in strength and in some cases disappear (Agnew \& Petersen, 1989; Holland \& Andre, 1987; Schafer, 1969).

The claim that structured youth activities promote positive developmental outcomes is more adequately tested by longitudinal studies. These, however, are few and many of them suffer the same possibility of confounding self-selection variables as the cross-sectional research. A number of studies analyzing data over long time periods suggest impressive long-term effects. They have found associations between high school and adult participation in political organizations (DeMartini, 1983), the arts (Bloom, 1985), and sports (Howell \& McKenzie, 1987) but do not adequately control for the possibility that prior, unmeasured third variables were 
driving these relationships. Studies that control for some of the variables that affect high school participation, such as SES, grade point average (GPA), and academic ability, still find effects, though modest in size. Hanks and Eckland (1978) found that youth who participated in extracurricular activities in high school were more likely to be involved in voluntary associations at age 30, even with controls for initial SES and academic aptitude. Glancy, Willits, and Farrell (1986) found participation in extracurricular activities to be associated with occupational attainment 24 years later, with controls for parents'SES and high school GPA.

The most rigorous test of the thesis is provided by shorter-term longitudinal studies in which dependent variables are measured on multiple occasions. This design allows investigators to assess whether participation in youth activities is related to within-person change for these dependent variables. Using this approach with a sample of 1,259 middle-class youth, Eccles and Barber (1999) found that participation in structured youth activities in 10th grade predicted positive changes in GPA between 10th and 12th grade. They also found that participation in team sports was related to a comparative increase in use of alcohol. Analyzing longitudinal data from a sample of 10,000 youths in the High School and Beyond Study, Marsh (1992) found significant relationships between participation in extracurricular and community activities and positive changes in self-concept, schoolwork, and educational and occupational aspirations from 10th to 12th grade. Marsh noted that the effect sizes were small, under one percent. But this may be because the impact of effective programs or activities is diluted by the lack of impact among weaker ones.

Effects can, in fact, be much larger for specific structured youth activities, as is demonstrated by research evaluating adventure programs, such as Outward Bound. Adventure programs are not the prototypic structured youth activity; they involve experiences of intense mental, physical, and interpersonal challenge in a wilderness setting, typically for a period of two to four weeks. They are, however, structured and voluntary. What is more, they easily lend themselves to rigorous pre-post evaluation. Hattie, Marsh, Neill, and Richards (1997) conducted a meta-analysis of evaluation data from 151 samples of participants, approximately one half of whom were schoolaged adolescents. Aggregating findings for 40 different types of outcome variables, they found a mean effect size of .34 across all samples and .26 for the adolescent samples. In a similar, although less comprehensive meta-analysis, Cason and Gillis (1994) found a mean effect size of .31 for adolescents. The strongest effect sizes in Hattie and associates' meta-analysis were for variables dealing with self-control, such as independence (.47), self-efficacy (.31), assertiveness (.42), internal locus of control (.30), and decision making (.47) — variables that relate to my construct of initiative. The most striking finding of their meta-analysis was that, unlike in most program evaluations, effect sizes increased rather than diminished in the 25 months following participation in the program. This suggests that participants may have acquired some new quality, such as initiative, that is generative of additional, post-program positive growth. 
This research on adventure programs is clearly the most compelling body of evidence that structured voluntary activities can have powerful, sustainable, positive effects on development, including what looks like development of initiative. But the differences in effect sizes between this and other youth activities also highlights how little we really know about what actually accounts for these changes. Several authors have lamented the absence of theory in this research and the lack of attention to process (Brown, 1988; Holland \& Andre, 1987; Oden, 1995). Most of this outcome research does not allow us to conceptualize or discriminate what processes or experiences create positive development in some activities but not in others.

The one set of processes that is discussed in some of this research, but not rigorously tested, is the sociological phenomenon of social integration into a group (Eccles \& Barber, 1999; Youniss, Yates, \& Su, 1997). Classic sociological theory recognizes that joining a group leads to processes of secondary socialization, which include assimilation of the group's norms and internalization of an identity associated with group membership (Berger \& Luckmann, 1966). In the case of youth activities, not only does a teen join the team, club, or activity group, but frequently other participants become part of the teen's peer friendship network (Brown, 1990), thus redoubling the opportunity and impetus for him or her to be socialized into group norms. Eccles and Barber suggested that the sequence is typically reflexive, that the choice to enter an activity may both grow out of and reinforce an adolescent's norms and emerging identity. Ethnographic studies provide in-depth descriptions of this socialization into group norms (Eder \& Parker, 1987; Fine, 1983, 1987).

The most extensive and most psychological discussion of these processes of social integration are provided by Youniss, Yates, and their colleagues, who have focused on how participation in service activities, an important subcategory of youth activities, is related to adolescents' development of civic participation. They argued that service activities provide a context for youth to observe and practice basic roles and processes of civic engagement (Youniss, McLellan, \& Yates, 1997). They also proposed that the formation of relationships with group members and adult leaders furnishes adolescents with valuable social capital (Youniss, Yates, \& Su, 1997). Furthermore, they suggested that experiences in service activities can provide provocative reflective material at a critical juncture in identity development that adolescents incorporate into their identity work (Youniss, McLellan, Su, \& Yates, 1999; Youniss \& Yates, 1997).

These processes of social integration are useful for making sense of outcome findings regarding normative behavior. Reduced delinquency, increased self-esteem, greater career aspirations, and even athletes' increased alcohol use may reflect socialization into group mores and identity, and the social capital acquired in an activity may facilitate continued participation and advancement in that activity after high school. As a psychologist, however, I find these processes less useful for explaining what seem like organismic developmental changes, such as the acquisition of initiative. With the exception of Youniss and Yates's (1997) discussion of identity develop- 
ment, these accounts do not seem very useful for explaining changes that increase after group membership ends, such as the rising effect sizes that follow participation in adventure programs. Recent research by Shirley Brice Heath (1999) provides a window on processes that are more internal, organismic, and better suited to explaining the development of initiative.

\section{A Language of Agency}

As a linguist, Heath has been interested in the oral communications of adolescents while they participate in structured voluntary activities. The speech samples she obtained provide a direct view of changes in adolescents' thought processes that reflect learning of initiative. Heath's research, conducted in collaboration with Milbrey McLaughlin and others, deals with youth participating in organizations that youth themselves have identified as being particularly attractive and effective (Heath, 1993; Heath \& McLaughlin, 1993; McLaughlin, Irby, \& Langman, 1994). Their sample of organizations included art and drama groups, sports teams, Boys and Girls Clubs, YMCA gang intervention programs, and other community organizations. All were in low-income neighborhoods, serving multiethnic groups of youth in urban, small-city, and rural settings. The researchers observed activities, interviewed participants, and recorded their language use.

Before discussing developmental changes in the youths' language, it is essential to provide a brief description of the psychological environments these organizations provided. These environments appeared to be structured to facilitate the three elements of initiative. First, these researchers found that all of these effective organizations were youth based: Although the original impetus for the groups came from adults, the motivation, direction, and goals of the groups' activities came from the participants. Adult leaders skillfully avoided assuming responsibility for the direction of the group, insisting that those decisions be made by participants (McLaughlin et al., 1994). A gentry was placed with the youth. Thus, rather than working toward goals set for them by adults, the participants held responsibilities for setting goals and identifying what problems needed to be solved. They held responsibility for raising money, writing grants, handling budgets, setting rules, and deciding schedules. These organizations depended upon the participants being intrinsically motivated, otherwise they quite literally went under (Heath, 1997).

A second feature of these effective organizations was that all of them engaged youth in an environment of real world constraints, and the leaders did not blanch from articulating these constraints. The coach of one Little League team that Heath studied repeatedly restated the rules of the game, including the constitutive rules of baseball and informal rules of strategy and good sportsmanship. He also continually asked players to recite these rules to encourage their internalization (Heath, 1994). In all of the organizations, the groups' work eventually led to some form of what Heath (1997) called" authentic evaluation," assessment of the group's product by an outside evaluator, criteria, or test. In other words, to the extent that partici- 
pants devoted attention to the activity, they were required to engage with challenge and complexity.

Third, all of the organizations studied involved an arc of activity over a period of time. In some cases it was a season, in others the period of time required to develop a production or performance. As a result, all involved stages of planning, practice, or rehearsal, followed by production, performance, or achievement of a goal (Heath, 1994; Heath \& Langman, 1994). This arc of activity frequently involved setbacks, obstacles, and emerging challenges, such as losing games, funding shortages, toilets overflowing in the organization's building, or the challenge of how to get 11 band members into a van when the insurance only covered 9 people (Heath, 1997). Therefore, youths were required to monitor and regulate the cumulative course of their actions.

These organizations, then, provided an environment of possibilities for planful action, for initiative. They provided a context that demanded self-directed constructive attention over time. What emerged within these environments was a language of agency. When adolescents first joined these organizations, they exhibited a type of language fitted to the bored youth that I described at the beginning of this article. They changed topics of conversation frequently, with few instances of sustained focus on a single topic. Their statements included almost no conjectures about future events and reflected a passive and self defensive orientation that viewed acts of initiative as inevitably doomed to failure. However, Heath $(1997,1999)$ reported marked changes in the language of young people in these organizations within their first three to four weeks of participation. Four types of language use increased that reflect skills to think about the world as a field of action.

To begin with, Heath found a dramatic increase in the use of conditionals, statements taking the form "If A, B, \& C, then X, Y, \& Z."These statements often laid out hypothetical scenarios for discussion and analysis."Let's imagine that...then what?" Scenarios typically situated the individual or group as actors. They dealt with likely outcomes that might ensue from different courses of action. "If we spend our budget on set design, how much money will we have left for costumes?" Or they dealt with types of actions that might be required should certain situations arise.

Along with more frequent conditionals, new participants increased their use of modals, such as" should," "could," and "would." "Could we do so and so? Would it work out?" Heath observed a dramatic increase in probabilistic thinking. Their language reflected a weighing of hypothetical possible actions against realistic likelihoods that those actions would have desired versus undesired consequences. They were developing the language skills of contingency thinking.

Next, new participants increased their use of strategies for getting clarification from others. In discussion with each other, or with outside people with whom they were engaged, they more often sought to sharpen their understanding of conditionals: "You mean if I do X, then...?"This reflects increased value placed on precise knowledge of consequences. For example, "If we rent the band shell, will the city 
give us access to electric jacks and bath rooms?" Contingency thinking requires accurate information about likely outcomes of actions.

Finally, Heath found that new participants expanded their use of varied genres and voices in their speech. They more frequently shifted registers in their statements, including adapting the perspective and language of board members, business leaders, reporters, and other adult worlds with which they interacted. Depending on the situation, they might use legalese, a care-giving register, or problem-solving language. In short, they became more able to play a variety of roles and take multiple perspectives (Heath, 1997, 1999). Heath (1993) reported that, when adapting the role of someone else, even shy youth showed an assertive confidence not evident when speaking as themselves.

What unites all four of these changes is the representation of thought and action in a world of contingencies and possibilities. These teens had learned to think of the world as similar to a chess board in play. They learned to perceive the array of strategic options and to estimate probable consequences associated with these options. In other terms, they had developed what I would call an operating language for initiative, with tools for anticipating, planning, adapting to others, monitoring progress, and adjusting behavior over time to achieve a goal. For most of the groups Heath studied, this language was learned in group contexts, reflecting the injunction from Rogoff et al. (1995) that the development of agency in these contexts often involves collective participation.

What Heath's work does, then, is begin to open the black box to internal transformations within participants, providing a window on what they are actually learning. It begins to make the processes of developmental change more tangible, including some of the processes that correspond to the development of initiative. These changes can be seen partly as secondary socialization: Leaders and older members modeled this operating language and new members, eager to be part of the group, internalized it (Heath, 1991, 1999; Heath \& Langman, 1994). But these changes also involve organismic, developmental processes. Participants did not merely acquire a language, they learned to adapt and use it generatively. Although the sociological account elucidates processes of social integration, this linguistic-psychological account gives us a handle on processes of personal integration. New participants appeared to undergo a paradigm shift in their way of thinking, reflecting qualitative developmental change. They appeared to have developed skills for implementing plans, for directing and regulating their activities over time. They ingested a new mode of action. Along with it, they reported feeling more self-efficacious, more confident in their ability to affect the world (Heath, 1997). Such a paradigm shift could provide an explanation of why youth in adventure programs show sustained and increased effects after the program is over; they acquire an operating language that is generative.

It is too soon to be certain how much this language change corresponds to actual behavioral change. As of yet, there is no evidence regarding its association 
with acts of initiative or anything else. Development of other constructs from the emerging social psychological literature on agency, such as implementation intentions and emotional self-regulation (Gollwitzer,1999; Mischel, Cantor, \& Feldman, 1996), might also be fruitfully tested in this context. Nonetheless, Heath's work provides a very promising start.

\section{CONCLUSION: YOUTH ACTIVITIES} AS DEVELOPMENTAL CONTEXTS

The thesis of this article has been that structured voluntary youth activities provide a fertile context for positive development, particularly the development of initiative. First, I showed that during youth activities, adolescents experience a unique combination of intrinsic motivation and concentration that is rarely present during their daily experiences in schoolwork and unstructured leisure. These two components of experience, I proposed, represent two critical elements of initiative, and when they occur in activities involving a temporal arc of action toward a goal, as is the case with many youth activities, all three elements for the experience and learning of initiative are in play. Second, I reviewed a range of outcome research that begins to confirm that such activities are indeed associated with positive outcomes, such as diminished delinquency, greater achievement, and increased self-control and self-efficacy. Some of these positive outcomes may be attributable to important sociological processes, such as secondary socialization into a group, but these processes were not adequate for explaining changes that appeared to be more internal and organismic. Thus, last, I presented Heath and colleague's work demonstrating that activity participation, at least in some cases, is related to acquisition of an operating language of agency. This gives us a window on organismic processes that might lie behind the positive outcomes associated with participation in structured youth activities, particularly the development of initiative. It suggests processes of personal integration that may work in tandem with the sociological processes of social integration.

The conditions that make structured youth activities a fertile context for the development of initiative, I believe, also make them a rich context for the development of an array of other positive qualities, from altruism to identity. Children and adolescents come alive in these activities, they become active agents in ways that rarely happen in other parts of their lives. This makes youth activities an invaluable laboratory for the study of processes of positive development, one that deserves much more scientific attention. Of course, positive development occurs across contexts - in school, with families, and with peers-but I hypothesize that this is a context in which there is often a higher density of growth experiences.

To advance knowledge of positive development, one useful avenue for developmental psychology would be to give youth activities equivalent status to school, family, and peers as a focal context of development. This might include comparable research funding and a separate chapter in developmental textbooks. True, this context accounts for much less of youths' daily time, but knowledge of developmental 
processes in this domain has the potential to have equal or greater impact on practice. It is essential of course, that research on this context be done in collaboration with youth development professionals, for there to be the type of interaction between science and practice that has been called for in applied developmental science (Fisher \& Lerner, 1994). I should also call attention to fruitful visions developed by others for such a field of research and practice (American Youth Policy Forum, 1997; Hamburg, 1997; Roth et.al., 1998).

An alternative avenue would be to envision positive youth development as a parallel (and closely aligned) field to developmental psychopathology, one that deals with positive development regardless of context. This might also be envisioned as a National Institute of Mental Health study section and a separate chapter in developmental textbooks. It would seek to integrate research on resiliency, initiative, emotional regulation, self-efficacy, identity, prosocial behavior, and moral development, among other topics. Although I do not want to diminish this later alternative (indeed, I would like to see both taken up), I spend the remainder of this conclusion drawing out the first proposal, because I think its focus on a specific context gives it more potential as a cohesive project. Here are some of the issues I see as foundational.

\section{Contexts}

A key to conceptualizing structured youth activities as developmental contexts is identifying the processes that occur in them, from learning an operating language to developing emotional skills to overcome disappointments. A major challenge to research and theory, however, is dealing with the heterogeneous array of extracurricular, community, and self-directed activities that can be included as youth activities, each harboring distinct opportunities and processes. From aerobics to service activities to creating a web site, the "treatment" is extremely varied. Some activities are collective and demand coordination with others, whereas others are solitary. Activities differ in the degree to which the goals and criteria for desirable performance are prescribed (gymnastics, school band) versus those in which participants have much freedom to create their own standards (plastic arts). Adolescents' activities on computer systems are particularly diverse in form, with some being structured and goal oriented and others requiring little cumulative effort over time. How do we categorize this array?

A useful starting point for conceptualizing and categorizing youth activities would be descriptive research that simply enumerates what types of process experiences participants typically have across different types of activities. How often do youth in swimming versus drama clubs versus service organizations have the experience of setting their own goals, developing plans, or empathizing with people from a dissimilar background to theirs? In gathering such enumeration, it would be useful to obtain parallel data for activities such as schoolwork, work at a job, and unstructured leisure activities, in order to test whether rates of these process experiences are indeed higher during youth activities. 


\section{Developmental and Individual Differences}

The occurrence of developmental processes in a given setting, of course, is not just a function of the context, but is a joint function of the context and the individual. What would be beneficial is theory and research that helps identify individuals' preparedness to engage in specific developmental processes. How might age, personality, culture, gender, and SES, among other factors, shape initial dispositions and how youths experience and participate in an activity?

The starting point for much developmental research has always been identifying ages at which specific skills are and can be mastered. For example, at what age are children or adolescents able to acquire the various elements of an operating language for initiative, such as the use of modals? Rogoff et al. (1995) observed that with age and experience, Girl Scouts had diminished needs for adult scaffolding in structuring their activities. Indeed, if one looks at the current array of structured activities available to youth, one sees that there is already a loose progression from activities in childhood, such as Brownies and Cub Scouts, that are highly structured by adults, to activities in high school, such as publishing a school newspaper, in which youths take much more responsibility for directing their action. More specific data on the ages at which youths are ready to master specific skills would be beneficial to the design of activities and, eventually, to knowledge that helps place individual youths in activities suited to their zone of proximal development. Other individual factors besides age need to be considered as well. For example, how do cultural differences in the construction of agency (Markus, Kitayama, \& Heiman, 1996) affect youth's participation and learning?

\section{Leading/Coaching}

Knowledge of the interplay between contexts and persons leads to the applied question of how leaders of structured voluntary activities can best facilitate developmental processes. Leaders face a fundamental problematic of allowing participants' actions to be self-directed, voluntary, and intrinsically motivated, yet also structured and challenging enough that participants are stretched into new domains of complexity. Leaders of Heath and colleagues' successful organizations tenaciously insisted that youths hold responsibility for major decisions of the organization, even when those decisions threatened the existence of the organization. But at the same time, these leaders played a role in defining the situation and modeling the language of agency. They laid out problems in the form of "what if' and "if then" contingencies. They prompted participants to think through alternative scenarios and hypothetical situations, posing open-ended dilemmas that required reflection, analysis, and drawing on past experience (Heath, 1991; Heath \& Langman, 1994; McLaughlin et al., 1994).

Research in coaching sports is the furthest along in providing empirically tested paradigms for addressing this fundamental problematic. Roberts and colleagues have found that many youth coaches create a performance-oriented motivational 
climate that is not conducive to development because it focuses athlete's attention on winning, public recognition, and performance relative to others. Athletes adapting this performance-focused orientation tend to think of talent as a native endowment and practice less, and their motivation flags when feedback suggests that they are less endowed with talent than others (Roberts \& Treasure, 1992; Roberts, Treasure, \& Kavussanu, 1997). In contrast, another set of coaches create a mastery-oriented climate that focuses athletes' attention on their development of skills relative to individualized standards. Athletes adapting this mastery orientation are more likely to see talent as something that results from practice, are more likely to persist in the face of difficulty, and show more skill development over the course of a season. These findings have had a direct impact on practice, leading to the development of techniques for coaches to work with athletes in setting goals for personal skill development that are independent of winning and losing (Roberts \&Treasure, 1992; Roberts et al., 1997). Coaches learn to support self-direction, while encouraging structures suited to mastery of new skills.

A next step is to evaluate how well this and other knowledge of coaching can be applied to leadership in nonsport youth activities. In addition, we might ask, how much existing knowledge about good teaching and good parenting can be applied? For example, are good leaders like authoritative parents, like childcentered teachers?

\section{Outcomes}

Outcome research is often a necessary evil that is done before anyone knows what to look for, and that has been the case in this domain as well. Evaluative data have been needed to justify funding for youth activities, even though we are not yet sure what the independent and dependent variables for this evaluative research should be. From a scientific perspective, the first priority needs to be descriptive and process research, done in collaboration with youth professionals, that helps to conceptualize what the developmental phenomena are. What is especially needed is longitudinal action research and qualitative research that follows the same individuals over time in order to develop models of change processes. A useful strategy for some types of activities would be to identify individuals and groups whose participation in an activity showed exemplary objective progress, then look backwards to these longitudinal data to see how their processes differed from those exhibited by individuals and groups who spun their wheels and showed less progress.

When the field is ready for quantitative outcome studies, they need to use a higher level of critical rigor than has often been the norm. This calls for research that evaluates the occurrence of processes as a function of activity, participants' developmental stages, and leadership variables, and how these processes are related to progressive change over time. Researchers must study and control for self-selection characteristics. Evaluations need to assess possible negative effects of participation in youth activities as well as positive ones. For example, research on participation 
in competitive sports suggests that they are associated with increased competition anxiety (Smoll \& Smith, 1996) and acquisition of more self-centered moral reasoning (Bredemeier \& Shields, 1996). Might these negative outcomes also occur in other demanding and competitive activities, such as in music competition?

The most strenuous evaluation research would test whether participation in an activity is related to effects outside the activity itself. I have argued that youth activities are a context for development of qualities and skills, like initiative, that have general applicability across domains of life. In a similar vein, Youniss, Yates, and Su (1997) hypothesized that participation in youth activities creates personal confidence that increases the participants'likelihood of engaging in public service in other contexts. Research evaluating these types of generalized, cross-context effects will be the most difficult to conduct, but will provide the most persuasive evidence.

\section{Practice}

The large applied discipline of psychotherapy currently exists to treat psychological problems. Imagine, if you will, a field of psychological practitioners whose knowledge, skills, and status are comparable with those of clinical psychologists, who have advanced training in diagnostics, mentoring, and program design, and who draw upon a well-developed body of research to provide guidance and counseling on positive human development. Such a field does not need to start de novo, as there are currently many youth development professionals. But it does need to evolve to incorporate a cumulative body of research and theory. One role of these practitioners would be to help place children, adolescents, and perhaps adults too in structured voluntary contexts that are suited to individuals' personality, developmental stage, and ability level. Another would be to provide process mentoring, to help keep people "in the envelope" of intrinsically motivated challenge and learning. Yet another role would be to design and run programs that maximize individual and group growth. Rather than leaving positive development in the hands of nonprofessionals, self-help gurus, and for-profit, ClubMed-type chains, we need a science and art, comparable with psychotherapy, regarding how to help people realize their full capacities across ages.

Research on coaching provides an example of the impressive payoffs that can result from a research-based, applied discipline of positive development. In observational studies, Smith and Smoll (1990) found favorable psychological outcomes to be greater for boys in Little League Baseball whose coaches engaged in high levels of positive reinforcement for both desirable performance and effort, who responded to mistakes with encouragement and technical instructions, and who emphasized the importance of fun and personal improvement over winning (Curtis, Smith, \& Smoll, 1979; Smith \& Smoll, 1990). On the basis of these and other findings, they then designed a three-hour training workshop for new coaches. Three hours is extremely short compared with most interventions; nonetheless, they found that athletes playing for the trained coaches reported substantially and significantly more 
enjoyment than did control participants, showed increases in self-esteem and decreases in performance anxiety over the course of the season, and were more likely to return the next season, with the biggest effects being for athletes who were low in self-esteem (Smith \& Smoll, 1997; Smoll, Smith, Barnett, \& Everett, 1993). If a three-hour intervention can have such long-term impact, imagine what might be accomplished with a body of research comparable in size and sophistication with that for developmental psychopathology.

As someone with a special interest in adolescence, my vision for the 21st century is a society in which youth have a rich range of expertly staffed structured activities to choose from, regardless of their SES, gender, ethnicity, sexual orientation, ability level, and type of interest. This would include activities during the school year and summer, and activities with links to businesses, professional arts, and civic organizations, so that youths develop connections that integrate them into adult society. Participation in these activities would be self-determined but supported and guided according to age, stage, learning style, and ability, so that youths are stretched to their full potential. Each activity would have enough structure so that youths are challenged, but also enough flexibility so that, as youths gain experience, they assume responsibility for the direction of the activity. As a result, participants progressively learn to internalize an operating language for sustaining their own motivation and directing and monitoring their actions over time, a language that is generative and that carries over, helping them to create order, meaning, and direction when they encounter ill-structured choices in other parts of their lives.

\section{References}

Agnew, R., \& Petersen, D. (1989). Leisure and delinquency. Social Problems, 36, 332-350.

Alsaker, F. D., \& Flammer, A. (1999). The adolescent experience in twelve nations: European and American adolescents in the nineties. Hillsdale, NJ: Erlbaum.

American Youth Policy Forum. (1997). Some things do make a difference for youth: A compendium of evaluations of youth programs and practices. Washington, DC: Author.

Anderman, E. M.. \& Maehr, M. L. (1994). Motivation and schooling in the middle grades. Review of Educational Research, 64, 287-309.

Balswick, J., \& lngoldsby, B. (1982). Heroes and heroines among American adolescents. Sex Roles, 8, 243-249.

Benedict, R. (1938). Continuities and discontinuities in cultural conditioning. Psychiatry, 1, 161-167. 
Berger, P. L., \& Luckmann, T. (1966). The social construction of reality: A treatise in the sociology of knowledge. Garden City, NY: Doubleday.

Bloom, B. (1985). Developing talent in young people. New York: Ballantine.

Brandtstiidter, J. (1998). Action perspectives on human development. In R. M. Lerner (Ed.), Theoretical models of human development. Hand book of child psychology, I (5). New York: Wiley.

Bredemeier, B. \& Shields. D. (1996). Moral development and children's sport. In F. Smoll \& R. Smith (Eds.), Children and youth in sport: A biopsychosocial perspective (pp. 381-401). Chicago: Brown \& Benchmark.

Brown, B. B. (1988). The vital agenda for research on extracurricular influences: A reply to Holland and Andre. Review of Educational Research, 58, 107-111.

Brown, B. B. (1990). Peer groups and peer cultures. In S. S. Feldman \& G. R. Elliot (Eds.), At the threshold: The developing adolescent (pp.171-196). Cambridge, MA: Harvard Press.

Butcher, J. (1985). Longitudinal analysis of adolescent girls' participation in physical activity. Sociology of Sport Journal, 2, 130-143.

Carli, M., Delle Pave, A., \& Massimini, F. (1988). The quality of experience in the flow channels: Comparison of Italian and U.S. students. In M. Csikszentmihalyi \& I. Csikszentmihalyi (Eds.), Optimal experience: Psychological studies of flow in consciousness (pp. 288-306). New York: Cambridge University Press.

Carnegie Council on Adolescent Development. (1992). A matter of time: Risk and opportunity in the nonschool hours. NewYork: Carnegie Corporation of NewYork.

Cason, D., \& Gillis, H. L. (1994). A meta-analysis of outdoor adventure programming with adolescents. Journal of Experiential Education, 17, 40-47.

Collins, W. A., \& Gunnar, M. R. (1990). Social and personality development. American Review of Psychology, 41, 387-416.

Csikszentmihalyi, M. (1975). Beyond boredom and anxiety: The experience of play in work and games. San Francisco: Jossey-Bass. 
Csikszentmihalyi, M. (1978). Attention and the wholistic approach to behavior. In K. S. Pope \& J. L. Singer (Eds.), The stream of consciousness (pp. 335-358). New York: Plenum.

Csikszentmihalyi, M. (1990). Flow: The psychology of optimal experience. New York: Harper-Collins.

Csikszentmihalyi, M. (1993). The evolving self: A psychology for the third millennium. New York: Harper-Collins.

Csikszentmihalyi, M. (1996). Creativity: Flow and the psychology of discovery and invention. New York: Harper-Collins.

Csikszentmihalyi, M., \& Larson, R. W. (1984). Being adolescent. New York: Basic Books.

Csikszentmihalyi, M., Rathunde, K., \& Whalen, S. (1993). Talented teenagers: The roots of success and failure. Cambridge, England: Cambridge University Press.

Curtis, B., Smith, R., \& Smoll, F. (1979). Scrutinizing the skipper: A study of leadership behaviors in the dugout. Journal of Applied Psychology, 64, 391-400.

Deci, E. L., (with Flaste, R.), (1995). Why we do what we do: The dynamics of personal autonomy. New York: Putnam.

Deci, E. L., \& Ryan, R. M. (1985). Intrinsic motivation and self-determination in human behavior. New York: Plenum.

DeMartini, J. (1983). Social movement participation: Political socialization, generational consciousness, and lasting effects. Youth and Society, 15, 195-223.

Dewey, J. (1913). Interest and effort in education. Carbondale: Southern Illinois University Press.

Dubas, J. S., \& Snider, B. A. (1993). The role of community-based youth groups in enhancing learning and achievement through nonformal education. In R. M. Lerner (Ed.), Early adolescence: Perspectives on research, policy, and intervention (pp. 150-174). Hillsdale, NJ: Erlbaum.

Eccles, J. S., \& Barber, B. L. (1999). Student council, volunteering, basketball, or marching band: What kind of extracurricular involvement matters? Journal of Adolescent Research, 14, 10-43. 
Eccles, J. S., \& Midgley, C. (1991). Changes in academic motivation and selfperception during early adolescence. In R. Montemayor, G. R. Adams, \& T. P. Gulotta (Eds.), From childhood to adolescence: A transitional period? (Advances in adolescent development: Vol. 2). Newbury Park, CA: Sage.

Eccles, J. S., Wigfield, A., \& Schiefele, U. (1998). Motivation to succeed. In W. Damon \& N. Eisenberg (Eds.), Handbook of child psychology: Vol. 3. Social, emotional, and personality development (5th ed., pp. 1017-1095). New York: Wiley.

Eder, D., \& Parker. S. (1987). The cultural production and reproduction of gender: The effect of extracurricular activities on peer-group culture. Sociology of Education, 60, 200-213.

Fine, G. A. (1983). Shared fantasy: Role-playing games as social worlds. Chicago: University of Chicago Press.

Fine, G. (1987). With the boys: Little League baseball and preadolescent culture. Chicago: University of Chicago Press.

Fisher, C. B., \& Lerner, R. M. (Eds.). (1994). Applied developmental psychology. New York: McGraw-Hill.

Gibson. E., \& Rader. N. (1979). Attention, the perceiver as performer. In G. Hale \& M. Lewis (Eds.), Attention and cognitive development (pp. 1-21). New York: Plenum.

Glancy, M., Willits, F., \& Farrell, P. (1986). Adolescent activities and adult success and happiness: Twenty-four years later. Sociology and Social Research, 70, 242-250.

Gollwitzer. P. M. (1999). Implementation intentions: Strong effects of simple plans. American Psychologist, 54, 493-503.

Hamburg, D. (1997). Toward a strategy for healthy adolescent development. American Journal of Psychiatry, 154(6), 7-12.

Hamilton, S. (1994). Employment prospects as motivation for school achievement: Links and gaps between school and work in seven countries. In R. K. Silbereisen \& E. Todt (Eds.), Adolescence in context: The interplay of family, school, peers, and work in adjustment (pp. 267-303). New York: SpringerVerlag. 
Hanks, M., \& Eckland, B. (1978). Adult voluntary associations and adolescent socialization. Sociological Quarterly, 19, 481-490.

Hattie, J., Marsh, H. W., Neill, J.T., \& Richards, G. E. (1997). Adventure education and outward bound: Out-of-class experiences that make a lasting difference. Review of Educational Research, 67, 43-87.

Hauser, S. T., \& Smith, H. F. (1991). The development and experience of affect in adolescence. Journal of the American Psychoanalytic Association, 39, 131-165.

Heath, S. B. (1991).“It's about winning!": The language of knowledge in baseball. In L. B. Resnick, J. M. Levine, \& S. D. Teasley (Eds.), Perspectives on socially shared cognition (pp. 101-124). Washington, DC: American Psychological Association.

Heath, S. B. (1993). Inner city life through drama: Imagining the language classroom. TESOL Quarterly, 27, 177-192.

Heath, S. B. (1994). The project of learning from the inner-city youth perspective. In F. A.Villarruel \& R. M. Lerner (Eds.), Promoting community-based programs for socialization and learning (New Directions for Child Development, Vol. 63, pp. 25-34). San Francisco: Jossey-Bass.

Heath, S. B. (1997). Language and work: Learning and identity development of older children in community settings (George Miller Committee Lecture), University of Illinois.

Heath, S. B. (1999). Dimensions of language development: Lessons from older children. In A. S. Masten (Ed.), Cultural processes in child development: The Minnesota symposium on child psychology Vol. 29 (pp. 59-75). Mahwah, NJ: Erlbaum.

Heath, S. B., \& Langman, J. (1994). Shared thinking and the register of coaching. In D. Biber \& E. Finegan (Eds.), Sociolinguistic perspectives on register (pp. 82-105). New York: Oxford University Press.

Heath, S. B., \& McLaughlin, M. W. (Eds.). (1993). Identity and inner-city youth: Beyond ethnicity and gender. New York: Teachers College Press.

Holland, A., \& Andre, T. (1987). Participation in extra-curricular activities in secondary school: What is known, what needs to be known? Review of Educational Research, 57, 437-466. 
Howell, F., \& McKenzie, J. (1987). High school athletics and adult sport-leisure activity: Gender variations across the life cycle. Sociology of Sport Journal, 4 , 329-346.

Isen, A. M. (1987). Positive affect, cognitive processes, and social behavior. In L. Berkowitz (Ed.), Advances in experimental social psychology: Vol. 20 (pp. 203253). New York: Academic Press.

Isen, A. M., \& Means, B. (1983). The influence of positive affect on decision-making strategy. Social Cognition, 2, 18-31.

Kirshnit, C. E., Ham, M., \& Richards, M. H. (1989). The sporting life: Athletic activities during early adolescence. Journal of Youth and Adolescence, 18, 601-615.

Larson, R. W. (1983). Adolescents' daily experience with family and friends: Contrasting opportunity systems. Journal of Marriage and the Family, 45, 737-750.

Larson, R. W. (1985). Emotional scenarios in the writing process: An examination of young writers' affective experiences. In M. Rose (Ed.), When the writer can't write: Studies of disruption in the composing process (pp. 19-42). New York: Guilford Press.

Larson, R. W. (1994). Youth organizations, hobbies, and sports as developmental contexts. In R. K. Silbereisen \& E. Todt (Eds.), Adolescence in context: The interplay of family, school, peers, and work in adjustment (pp. 46-65). New York: Springer-Verlag.

Larson, R. W., Ham, M., \& Raffaelli, M. (1989). The nurturance of motivated attention in the daily experience of children and adolescents. Advances in motivation and achievement: Vol. 6. Motivation enhancing environments (pp. 45-80). Greenwich, CT: JAI Press.

Larson, R. W., \& Kleiber, D. (1993a). Daily experience of adolescents. In P. Tolan \& B. Cohler (Eds.), Handbook of clinical research and practice with adolescents (pp. 125-145). New York: Wiley.

Larson, R. W., \& Kleiber, D. A. (1993b). Structured leisure as a context for the development of attention during adolescence. Loisir et Societe! Society and Leisure, 16, 77-98.

Larson, R. W., \& Kubey, R. (1983). Television and music: Contrasting media in adolescent life. Youth and Society, 15, 13-31. 
Larson, R. W., \& Richards, M. H. (1991). Boredom in the middle school years: Blaming schools versus blaming students. American Journal of Education, 99, 418-443.

Larson, R. W., \& Verma, S. (1999). How children and adolescents spend time across the world: Work, play and developmental opportunities. Psychological Bulletin, 125, 701-736.

Leone, C. M., \& Richards, M. H. (1989). Classwork and homework in early adolescence: The ecology of achievement. Journal of Youth and Adolescence. 18, 531-548.

Lerner, R., \& Busch-Rossnagel, N. (1981). Individuals as producers of their development. New York: Academic Press.

Little, B. R. (1983). Personal projects: A rationale and method for investigation. Environment and Behavior, 15, 273-309.

Little, B. R. (I 998). Personal project pursuits: Dimensions and dynamics of personal meaning. In P.T. P. Wong \& P. S. Fry (Eds.), The human quest for meaning: A handbook of psychological research and clinical applications (pp. 193-212). Mahwah, NJ: Erlbaum.

Markus, H. R., Kitayama, S., \& Heiman, R. J. (1996). Culture and"basic" psychological principles. In E. T. Higgins \& A. W. Kruglanski (Eds.), Social psychology: Handbook of basic principles (pp. 857-913). New York: Guilford Press.

Marsh, H.W. (1992). Extracurricular activities: Beneficial extension of the traditional curriculum or subversion of academic goals? Journal of Educational Psychology, 84, 553-562.

McCormack, J. (1984). Interpersonal influences and the channeling of goals in adolescence. Unpublished doctoral dissertation, University of Chicago.

McLaughlin, M. W., Irby, M. A., \& Langman, J. (1994). Urban sanctuaries: Neighborhood organizations in the lives and futures of inner-city youth. San Francisco: Jossey-Bass.

McNeal, R. B. (1995). Extracurricular activities and high school dropouts. Sociology of Education, 68, 62-81. 
Mischel, W., Cantor, N., \& Feldman, S. (1996). Principles of self-regulation: The nature of willpower and self-control. In E.T. Higgins \& A.W. Kruglanski (Eds.), Social psychology: Handbook of basic principles (pp. 329-360). New York: Guilford Press.

Nurmi, J. (1991). How do adolescents see their future? A review of the development of future orientation and planning. Developmental Review, 11, 1-59.

Oden. S. (1995). Studying youth programs to assess influences on youth development: New roles for researchers. Journal of Adolescent Research, 10, 173-186.

Oettingen, G. (1997). Culture and future thought. Culture E Psychology, 3, 353-381.

Ogbu. J. U. (1991). Racial stratification and education in the United States: Why inequality persists. Teachers College Record, 96, 254-298.

Richards, M. H., \& Larson. R. W. (1998). Daily experience and mental health of youth at risk. Unpublished raw data.

Roberts, G. C., \& Treasure, D. C. (1992). Children in sport. Sport Science Review, 1(2), 46-64.

Roberts, G. C., Treasure, D. C., \& Kavussanu, M. (1997). Motivation in physical activity contexts: An achievement goal perspective. Advances in Motivation and Achievement, 10, 413-447.

Rogoff, B., Baker-Sennett, J., Lacasa, P., \& Goldsmith, D. (1995). Development through participation in sociocultural activity. Cultural practices as contexts for development: New Directions for Child Development, 67(Spring), 45-65.

Roth, J., Brooks-Gunn, J., Murray, L., \& Foster, W. (1998). Promoting healthy adolescents: Synthesis of youth development program evaluations. Journal of Research on Adolescence, 8, 423-459.

Ryan. R. M. (1993). Agency organization: Intrinsic motivation, autonomy, and the self in psychological development. The Nebraska Symposium on Motivation, 40, 1-56.

Ryan. R. M., Sheldon, K. M., Kasser, T., \& Deci, E. L. (1996). All goals are not created equal: An organismic perspective on the nature of goals and their regulation. In P. M. Gollwitzer \& J. A. Bargh (Eds.), The psychology of actions: Linking cognition and motivation to behavior (pp. 7-26). NewYork: Guilford Press. 
Sampson, E. E. (1988). The debate on individualism: Indigenous psychologies of the individual and their role in personal and societal functioning. American Psychologist, 43, 15-22.

Schafer, E. E. (1969). Participation in interscholastic athletics and delinquency: A preliminary study. Social Problems, 17, 40-47.

Schlegel, A., \& Barry, H. (1991). Adolescence: An anthropological inquiry. New York: Free Press.

Schneider, B., \& Stevenson, D. (1999). The ambitious generation: America's teenagers, motivated but directionless. New Haven, CT:Yale University Press.

Seligman, M. (1990). Learned optimism: How to change your mind and your life. NewYork: Simon \& Schuster.

Silbereisen, R. K., Noack, P., \& Eyferth, K. (1986). Place for development: Adolescents, leisure settings, and developmental tasks. In R. K. Silbereisen, K. Eyferth, \& G. Rudinger (Eds.), Development as action in context: Problem behavior and normal youth development (pp. 87-107). New York: Springer-Verlag.

Simmons, R., \& Zhou, Y. (1994). Racial, school, and family context among adolescents. In R. K. Silbereisen \& E. Todt (Eds.), Adolescence in context: The interplay of family, school, peers, and work in adjustment (pp. 149-175). New York: Springer-Verlag.

Smith, R. E., \& Smoll, F. L. (1990). Self-esteem and children's reactions to youth sport coaching behaviors: A field study of self-enhancement processes. Developmental Psychology, 26, 987-993.

Smith, R. E., \& Smoll, F. L. (1997). Coaching the coaches: Youth sports as a scientific and applied behavioral setting. Current Directions in Psychological Science, 6, 16-21.

Smoll, F. L., Smith, R. E., Barnett, N. P., \& Everett, J. J. (1993). Enhancement of children's self-esteem through social support training for youth sport coaches. Journal of Applied Psychology, 78, 602-610.

Wilson, W. J. (1996). When work disappears: The world of the new urban poor. New York: Vintage Books. 
Winnie, P. H., \& Walsh, J. (1980). Self-concept and participation in school activities reanalyzed. Journal of Educational Psychology, 72, 161-166.

Youniss, J., McLellan, J. A., Su, Y., \& Yates, M. (1999). The role of community service in identity development: Normative, unconventional, and deviant orientations. Journal of Adolescent Research, 14, 248-261.

Youniss, J., McLellan,J. A., \&Yates, M. (1997). What we know about engendering civic identity. American Behavioral Scientist, 40, 620-631.

Youniss, J., \& Yates, M. (1997). Community service and social responsibility in youth. Chicago: University of Chicago Press.

Youniss, J., Yates, M., \& Su, Y. (1997). Social integration: Community service and marijuana use in high school seniors. Journal of Adolescent Research, 12, 245-262.

Work on this article was partly supported by National Institute of Mental Health Grant IROI MH57938. 